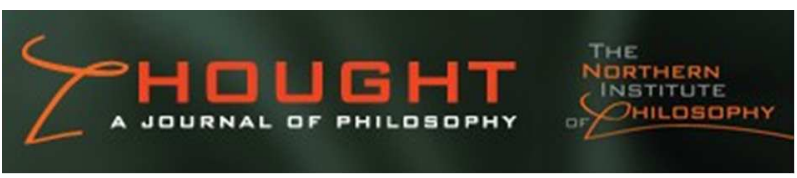

\title{
Pejorative Discourse is not Fictional
}

\begin{tabular}{|c|l|}
\hline Journal: & Thought: A Journal of Philosophy \\
\hline Manuscript ID & Draft \\
\hline Wiley - Manuscript type: & Research Article \\
\hline Keywords: & $\begin{array}{l}\text { Pejoratives, Fictionalism, Nonderogatory uses, Conversational implicature, } \\
\text { Blameworthiness }\end{array}$ \\
\hline Abstract: & $\begin{array}{l}\text { Hom and May argue that pejoratives mean negative prescriptive properties } \\
\text { that externally depend on racist ideologies, and that this entails a form of } \\
\text { fictionalism: pejoratives have null extensions. This paper argues that } \\
\text { pejorative discourse is not fictional. There are relevant uses of fictional } \\
\text { terms that are necessary to describe the content of fictions, and to make } \\
\text { true statements about the world, that do not convey that speakers are } \\
\text { committed to the fiction. The paper shows that the same constructions with } \\
\text { pejoratives typically convey that the speaker is committed to racist } \\
\text { ideologies, in contrast with fictional discourse that typically does not. The } \\
\text { disanalogy undermines the plausibility of fictionalism about pejoratives. } \\
\text { Moreover, the exceptions - uncommitted uses in embedded constructions - } \\
\text { display features that conflict with Hom and May's explanation of committed } \\
\text { uses as conversational implicatures }\end{array}$ \\
\hline
\end{tabular}

\section{SCHOLARONE ${ }^{\text {M }}$}




\title{
Pejorative discourse is not fictional
}

\begin{abstract}
Hom and May argue that pejoratives mean negative prescriptive properties that externally depend on racist ideologies, and that this entails a form of fictionalism: pejoratives have null extensions. This paper argues that pejorative discourse is not fictional. There are relevant uses of fictional terms that are necessary to describe the content of fictions, and to make true statements about the world, that do not convey that speakers are committed to the fiction. The paper shows that the same constructions with pejoratives typically convey that the speaker is committed to racist ideologies, in contrast with fictional discourse that typically does not. The disanalogy undermines the plausibility of fictionalism about pejoratives. Moreover, the exceptions - uncommitted uses in embedded constructions - display features that conflict with Hom and May's explanation of committed uses as conversational implicatures.
\end{abstract}

\section{Introduction}

Pejoratives offend and insult. Prima facie, they slur the people they refer to. According to Hom $(2008,2012)$ and Hom and May $(2013,2015)$ pejoratives express complex socially constructed negative properties that are determined in virtue of standing in causal external relations to racist ideologies and social practices. The negative properties expressed are prescriptive - they recommend certain attitudes and behavior. But no one should be subjected to those attitudes or behavior, and thus pejoratives have empty extensions. Hom and May argue that this means that pejoratives are neither co-intensional nor co-extensional with their neutral counterparts. Sentences like 'Jews are kikes' are false, because 'kike' has a null extension. Although people who use a slur may presume that they refer to certain people, they are mistaken - there are no such people. In the relevant respects, Hom and May claim, 'kike' is like 'unicorn', a situation that would justify fictionalism about pejoratives.

The aim of this paper is to show that there is an important disanalogy between fictional discourse and pejorative discourse. This disanalogy undermines fictionalism about pejoratives. Moreover, the exceptions - uncommitted uses in embedded constructions - conflict with Hom and May's explanation of committed uses as conversational implicatures. $\S 2$ presents the central claims under discussion, $\S 3$ argues for the disanalogy between fictional and pejorative discourse. $\S 4$ suggests that Hom and May's non-derogatory uncommitted uses 
display features that conflict with their explanation relying on conversational implicatures.

\section{The Semantic Strategy for Pejoratives, Ideol- ogy and Social Practices}

Hom $(2008,2012)$ offered a semantic account of the content of racial epithets - Combinatorial Externalism (CE). The derogatory content of an epithet like 'kike', for instance, is part of its literal semantic meaning, and is expressed in every context of utterance. This reveals that 'kike' and 'Jew' don't have the same meaning.

'Kike' = a pejorative for Jews.

'Jew' = the non-pejorative term for a group of people (determined by their ascendency/religion).

$\mathrm{CE}$ is externalist about the meaning of pejoratives. The external factors that determine the meaning of pejoratives are racist ideologies, along with the discriminatory practices that the ideologies support, not speakers' intentions or beliefs.

Hom and May $(2013,2015)$ uphold the central aspects of CE, namely that the normative meaning of a pejorative depends on social ideologies, that the meaning of pejoratives and their neutral counterparts are different, and that pejoratives and their counterparts are not co-extensional because pejoratives have null extensions. They conclude that these claims support the moral and semantic innocence view of pejoratives. According to moral and semantic innocence,

There are no kikes because there is no one who ought to be the object of negative moral evaluation just because they are Jewish. (Hom and May, 2013, 295)

In other words, (1) is false whereas (2) is true.

(1) Jews are kikes.

(2) Jews are not kikes.

Hom and May (2015) want to give a unified semantic account of all sentences containing pejoratives. Now, the uses of pejoratives in embedded and unembedded contexts typically induce squeamishness (Hom, 2008, 435), and are usually perceived as offensive. Hom and May distinguish between derogatory committed uses and non-derogatory uncommitted uses of pejoratives.

Hom and May (2015) claim that the offensiveness of slurs is over-generated, and is merely a 'psychological phenomenon' (Hom and May, 2013, 310). This psychological effect, they argue, is a conversational implicature in which the speaker is committed to the non-empty extensionality of the predicate, and in 
which the speaker accepts that the targets of the pejorative are worthy of contempt. The speaker thereby implicates that she is committed to the underlying racist ideology (Hom and May, 2013, 310). ${ }^{1}$ The use of the word conversationally implicates that the speaker is talking from an internal point of view. ${ }^{2}$ The conversational implicature is generated unless the speaker explicitly cancels it, or unless it is common ground that the implicature is false.

Recently, Hom and May (2015) argued that pejoratives are like fictional terms, since fictional terms also have null extensions (Hom and May, 2015, 1). 'Kike', they claim, is like 'unicorn' or 'Sherlock Holmes'. Atomic declarative sentences containing fictional names are false, although meaningful. Just as fictional propositions are essentially inapt for material truth, so are pejorative propositions. ${ }^{3}$ Let us call this view fictionalism about pejorative discourse.

Fictionalism about scientific theories that postulate unobservable theoretical entities is the anti-realist view that scientists talk as if scientific laws are true, and as if theoretical entities exist; but theoretical terms for unobserved theoretical entities do not actually refer, and scientific laws are not actually true. Fictionalism about pejorative discourse is the anti-realist view that racists talk as if racial epithets refer, although they are mistaken in doing so, because racist epithets have null extensions. As Szabó (2001) says,

To be a fictionalist about $F$ s is to think that our naïve attitude toward $F$-discourse is only halfway correct: we are right in thinking that we use genuine singular terms that purport to refer to $F \mathrm{~s}$, but wrong in thinking that they actually succeed in referring. In engaging in $F$-discourse we inadvertently slip into fictional talk. (Szabó, 2001, 294)

The next section shows that there is a crucial disanalogy between fictional and pejorative discourse, which undermines fictionalism about pejoratives.

\section{Fictionalism and Types of Fictional Discourse}

Fictional terms contribute in different ways to the meaning and truth-value of the sentences where they occur. Not all such possible uses are part of works of fiction. Some are true descriptions of the content of fictions, and some are true statements about the world. Significantly, these true statements do not signal

\footnotetext{
${ }^{1}$ The inference of the conversational implicature would seem to require that the meaning of the pejorative is available to the speakers, but this is in possible conflict with the externalist claim that the meaning of the pejorative meanings does not depend on the speakers' intentions or beliefs.

${ }^{2}$ The distinction between internal and external normative statements is common for instance in legal theory where, after Hart (2012), theorists distinguish between internal legal statements, made from the point of view of officials in a jurisdiction, and external legal statements that are descriptive of what the law is at a jurisdiction.

${ }^{3}$ Normally, 'inapt for material truth' means not truth-valued, i.e., inapt for either truth or falsehood. This conflicts with the naïve semantic innocent view according to which (1) above is false, and its negation (2) is true.
} 
that the speaker (or the reader) is engaged with the fiction, but merely that the speaker is describing aspects of reality.

Bonomi (2008) distinguishes the three possible uses of fictional terms.

Textual Sentences which are part of the text itself. E.g.: Sherlock Holmes seemed delighted at the idea of sharing his rooms with me. (Conan Doyle, A Study in Scarlet)

Paratextual Sentences by means of which we can state something true (or false) on the basis of the story narrated. E.g.: According to Conan Doyle's A Study in Scarlet, Sherlock Holmes seemed delighted at the idea of sharing his rooms with Dr. Watson.

Metatextual Sentences used to make true statements in the context of the real world. E.g.: Kareem Abdul-Jabbar loves Sherlock Holmes.

When Conan Doyle writes 'Holmes lives in Baker Street', he is uttering a sentence which, taken literally, is supposed to refer to a person called 'Holmes', and to ascribe a certain location in space to his lodgings. No reinterpretation is required to understand the sentence that Conan Doyle is uttering, and none would be adequate in order to understand it. He is putting forward an untrue claim, because of the lack of reference of the singular term 'Holmes'. However, Conan Doyle is not purporting to assert an untrue claim of this kind, still less presuming to be in a position to know it. He is doing something else, he is engaging with fiction-making.

According to van Fraassen (1980), the proponents of scientific theories are doing something similar. Van Fraassen holds that scientific claims about observable entities must be true, but that scientific claims about what is unobservable can be both adequate and untrue. He characterizes realism about scientific theories as the position that holds the following three claims (van Fraassen, 1980, 12):

(i) Scientific theories should be interpreted at face value. 'There are quarks' makes the same kind of claim as 'there are cans of beer in the fridge': there is no reinterpretation.

(ii) Scientific theories purport to be true.

(iii) We may in principle have good reasons for believing that a scientific theory is true.

Anti-realists may require a reinterpretation of the central terms of the theory, but still hold (ii) and (iii) as correct. Alternatively, a fictionalist anti-realist can maintain (i), but reject (ii) and (iii). The sentences in the theory are interpreted at face value, but are not true.

Interestingly, the three types of use of fictional terms that Bonomi (2008) identifies can be discriminated within a fictionalist view of scientific discourse. If we are fictionalists about unobservable theoretical entities, there will be textual, paratextual, and metatextual uses of terms like 'quarks'. Compare: 
Textual Sentences which are part of science. E.g.: Quarks combine to form hadrons.

Paratextual Sentences by means of which we can state something true (or false) on the basis of the theory. E.g.: According to the Standard Model of particle physics, quarks combine to form hadrons. A speaker can be committed to its truth, but uttering the sentence does not signal that she is committed to the background theory sustaining the meaning of the scientific terms.

Metatextual Sentences used to make true statements in the context of the real world. E.g.: Quarks were independently proposed by physicists Murray Gell-Mann and George Zweig in 1964. A speaker can be committed to its truth, but uttering the sentence does not signal that the speaker is committed to the background theory sustaining the meaning of the scientific terms.

There is a difference in fictional textual discourse between hermeneutical and revolutionary fictionalism (Burgess (1983), Stanley (2001).) Hermeneutic fictionalism about an area of discourse is a thesis that states that speakers do not actually aim at literal truth, but only pretend to do so. This is an apt description of what Conan Doyle did in writing the Sherlock Holmes novels. Revolutionary fictionalism about an area of discourse states that speakers who engage with that area of discourse ought only to make pretend-assertions. This is what anti-realist fictionalists about unobservable postulates of science claim scientists should be doing.

Whether or not one is a fictionalist about scientific entities, textual uses of scientific terms conversationally implicate that a speaker is committed to terms having a non-null extension, and therefore that they accept the underlying theory. Yet, paratextual and metatextual uses do not implicate any such commitment of the speaker. ${ }^{4}$

According to Hom and May's fictionalism about pejorative discourse, a textual use of a pejorative implicates that the speaker is committed to the racist ideology:

Offensiveness can be linguistically triggered, because when speakers use predicates, they typically conversationally implicate their commitment to the non-null extensionality of the predicate. (Hom and May, 2013, 310)

The best model for Hom and May is revolutionary fictionalism, which, in the case of scientific terms, predicts that in many textual uses there is an implication that the speaker, not herself a fictionalist, takes the terms not be empty. Granting this, the same clearly doesn't apply to corresponding paratextual and metatextual sentences. But there is a disanalogy between scientific terms and pejoratives. The implicature (if that is what it is) is also typically present in paratextual and metatextual discourse. Contrast:

\footnotetext{
${ }^{4}$ Utterances of those sentences are of course compatible with the speaker turning out to be committed to the truth of a theory, but this commitment is not required.
} 
Textual Prima facie, textual pejorative sentences are sentences like, e.g.: Kikes are untrustworthy. According to fictionalism, sentences like this are not apt for material truth.

Paratextual Paratextual pejorative sentences should be sentences by means of which we truly state the content of anti-Semitic ideology. E.g.: According to the alt-right media, kikes are untrustworthy. Paratextual uses of fictional terms can be true, and a speaker can be committed to its truth, but uttering the sentence should not signal that the speaker is committed to the background ideology sustaining the slur.

Metatextual Metatextual sentences should be sentences by means of which we make true statements in the context of the real world. E.g.: Jones loves kikes. A speaker can be committed to its truth, but uttering the sentence should not signal that the speaker is committed to the background ideology sustaining the slur.

If fictionalism about pejorative discourse were correct, the three sentences above should reveal not only differences in truth-values, but also differences in derogatory commitment.

Similar implicatures exist in textual uses of fictional words and uses of pejoratives. Non-enlightened users of scientific textual discourse assume that their theoretical terms refer. For instance, a physicist's use of the sentence quarks combine to form hadrons in a lecture conversationally implicates that the lecturer is committed to the non-empty extension of the terms used, and hence accepts the theory she is teaching.

In paratextual and metatextual uses of fictional words there is no implicature (or presupposition) that the speaker is committed to the scientific theory or engaged with the fiction. However, paratextual and metatextual pejorative constructions derogate and are offensive. They all convey a committed point of view (whether or not the speaker is actually committed).

In the paratextual case, we should expect the speaker to be committed only to the truth of the sentence According to the alt-right media, kikes are untrustworthy. But by uttering this sentence the speaker also communicates that she accepts anti-Semitic ideology. Yet, a report like According to the Standard Model of particle physics, quarks combine to form hadrons does not communicate that the speaker is committed to the truth of the claims of the Standard Model of particle physics, or to the existence of unobservable theoretical entities.

Metatextual uses like quarks were independently proposed by physicists Murray Gell-Mann and George Zweig in 1964 do not implicate that the speaker accepts that there are quarks. By contrast, Jones loves kikes derogates Jewish people, and indicates that the speaker has racist attitudes (whether or not the speaker actually has any).

There is hence an important and unexplained disanalogy between genuine fictional discourse and pejorative discourse. The only explanation that Hom \& May offer that could apply here - that there is a presumption that the speaker subscribes the underlying racism - is precisely what draws attention to the 
difference between fictional and pejorative discourse. Whereas only textual fictional uses implicate that the speaker is engaged with the fictional narrative, typically the three constructions with pejoratives sound offensive, even to us, the theorists reading the examples.

We have to replace the pejorative with a neutral counterpart to describe the content of the ideology or of aspects of the world (like the beliefs of racists) in non-derogatory non-committed ways:

(3) According to the alt-right media, Jewish people are untrustworthy.

(4) Jones believes that Jewish people are less trustworthy than Chinese people.

Hom and May could claim that the normative meaning of pejoratives is what explains why their use typically conversationally implicates committed readings whereas non-prescriptive fictional discourse doesn't.

When people make a normative statement like (5), or use a thick value term ${ }^{5}$ as in (6) or (7), they normally implicate that they accept the supporting social norm:

(5) You shouldn't interrupt when someone else is speaking.

(6) It is rude to interrupt when someone else is speaking.

It was rude of me to interrupt you just now.

Yet, normative statements can also be made externally, i.e., as uncommitted descriptions of existing norms. (8), (9), and (10) don't implicate that the speaker is committed to German social norms.

(8) According to German social norms, you shouldn't interrupt when someone else is speaking.

(9) According to German social norms, it is rude to interrupt when someone else is speaking.

(10) According to German social norms, I was rude for interrupting you just now.

These examples do not conversationally implicate that the speaker is committed to German social norms. They could have had that implicature if the speaker were German or speaking in Germany.

The disanalogy between fictional and pejorative sentences points to an underlying problem with the motivation for fictionalism about pejorative discourse. Fictionalism about a given domain, for instance scientific theories, is independently motivated by anti-realism about certain entity types, for instance unobserved theoretical entities.

\footnotetext{
${ }^{5}$ The distinction between thick value words and thin value words originates in the work of Bernard Williams (1985). Thick value words, like 'rude' or 'brave' combine an evaluative and a non-evaluative descriptive content, whereas thin value words like 'good' would be only evaluative.
} 
Hom and May (2015) claim that the content of pejoratives is expressible as a prescriptive predicate: ought to be the target of negative moral evaluation because of being a $G$ (Hom and May, 2015, 7). But prescriptions for socially determined groups do not single out an entity type which we, prima facie, have independent reasons to be skeptical about, unless we are deontic nihilists. Hom and May are not moral or deontic nihilists.

Suppose someone expresses her strong moral disapproval of Flynn's behavior by derogating him with the sentence in (9):

Flynn is a fucking traitor.

The speaker believes that whoever commits treason against their own countries ought to face criminal charges, and are also rightly targeted for negative moral evaluation. Being a traitor instantiates the prescriptive property form ought to be the target of negative moral evaluation because of being $a G$.

The group $G$ in that case is not ethnical, religious, or racial. But a religious group could deserve negative moral evaluation. Members of Aum Shinrikyo, the apocalyptic sect responsible for the sarin gas attack in the Tokyo subway in 1995, for instance, deserve moral condemnation. It may be disputed whether it is only their actions, and not their status as members of the sect, that deserves condemnation, but I'm not sure that's correct. Simple affiliation with certain groups might very well suffice to be contemptible, whatever group thinks merits disapproval: the nazis, the red brigades, ETA, the IRA, Aum Shinrikyo. It is not impossible that members of a social group $G$ are worthy of contempt because of being $G$ s.

Jeshion (2013) raises an objection based on similar cases, 'pimp' and 'fucking Nazi'. As she points out, whether or not an expression is semantically a pejorative can't depend on whether the target group is deserving of moral disapproval. Rather, it must depend on semantic features of the expression itself (Jeshion, 2013, 326-327).

It follows that negative prescriptive properties that target social groups have possible extensions, and in some cases actual extensions, for instance 'traitor', 'pimp', 'Nazi', or 'member of Aum Shinrikyo'. Hence, fictionalism about prescriptive properties of the form ought to be the target of negative moral evaluation because of being a $G$ is unmotivated.

Hom and May antecipate this objection. They say,

Note that we do not mean to preclude that it might be good reason for negative moral evaluation... that an individual is a member of a certain group, as opposed to just having certain objectionable personal properties or attitudes. In a certain sense, mass murderers form a group, and being a mass murderer justifies negative moral evaluation in virtue of the action one must take in order to become a member of that group. Being a member of that group, however, does not justify being the target of pejoration. (Hom and May, 2015, 8) 
The point here is whether being a member of a group $G$ may suffice for blameworthiness. I think there are many actual instances where we do disapprove of people just because of their group membership, without needing further information about their actions, beliefs, or intentions. I think we are often, even if not always, justified in blaming people just for group membership - "how could you possibly sign up for that? What were you thinking?" Moreover, even if we are not actually justified in the cases where we have blamed someone based on their group membership, it is still possible that there are groups such that membership in $G$ is in itself blameworthy.

\section{Uncommitted uses: cancelled implicatures, can- celled presuppositions, or quotational contexts?}

Although Hom and May acknowledge that pejoratives normally "scope out", as in the paratextual and metatextual constructions in the previous section, they also give examples of non-derogatory non-appropriated uses. They account for committed derogatory uses as conversationally implicating that the speaker commits to the non-empty extension of the pejorative, and as a result implicating that the speaker commits to the ideology. Conversational implicatures can be explicitly cancelled, or can fail to be inferred if it is clear that the common ground defeats them.

Below I adapt some of Hom's examples

Antisemitic institutions that treat Jewish people as kikes are morally depraved.

The example in (12) presumably cancels out the implicature by denouncing the treatment in question as morally depraved. And the example in (13) presumably defeats the implicature, assuming that the parenthetical remark that the speaker is Jewish defeats the implicature that the speaker accepts anti-Semitic ideology.

The existence of these non derogatory non-appropriated uses does not undermine my argument that there is a disanalogy between pejorative discourse and fictional discourse. If we contrast (12) and (13) with (8), (9), and (10) the disanalogy in normative commitments becomes clearer.

Following Hom and May's conversational implicature explanation, (12) and (13) are not committed readings because information that contradicts the implicature cancels the committed derogatory reading. That information is either that antisemitism is morally depraved, or that the speaker is herself Jewish. But in (8), (9), and (10) we have the inverse situation. The sentences do not display any committed internal reading to begin with, and we would need additional information from context to conversationally infer any committed reading. For instance,

\footnotetext{
${ }^{6}$ These cases modify examples (27) and (28) in Hom (2012), p. 388.
} 
According to German social norms, it is rude to interrupt when someone else is speaking. [uttered in Germany]

My mother says that I was rude for interrupting you. [uttered by a young German speaker]

Although Hom and May claim that there are other non-derogatory uses, it's unclear what explains non-derogatory cases in general. In general, adding 'uttered by a Jewish person' does not always have the neutralizing/cancelling effect it is meant to have in (13), as (16) shows

$$
\text { Kikes will receive bomb threats. [uttered by a Jewish person] }{ }^{7}
$$

The evidence provided by these cases raises doubts about the appeal to conversational implicatures. In (12) and (13), the pejorative is embedded under an operator - to treat $X$ as $Y$, or $S$ thinks that... Presuppositional inferences are typically cancellable by direct denial only when the presupposition trigger is embedded under another operator (Gazdar (1979)). Although there is no explicit denial in (12) or (13), the denial of the presupposition is inferable either from the information explicitly provided, or from context. This would suggest a presuppositional account, not a conversational implicature account, of the derogatory character of pejoratives.

In contrast, the non-derogatory uses (12) and (13) are the result of the implicitly quotational contexts where they occur. Bianchi (2014) argues for an echoic explanation of non-derogatory appropriated uses. If non-derogatory non-appropriated uses occur in quotational contexts, then pejoratives in those contexts are mentioned and not used. Cepollaro (2015) says that slurs that are not used but mentioned are not relevant non-derogatory uses, for the very reason that they are mentioned (Cepollaro, 2015, 41, n. 20), as academic articles like the present paper illustrate.

\section{In summary}

Metatextual and paratextual uses of names for unobserved theoretical entities do not conversationally implicate that the speaker accepts that those scientific terms have non-empty extensions, nor that the speaker accepts the underlying scientific theory as true. However, similar sentences with pejoratives typically convey that the speaker is committed to the ideology supporting the pejorative.

The difference between the fictional and the pejorative cases can't be explained by the prescriptive or normative nature of pejoratives. Normative claims of the form you shouldn't do $\phi$ or it is rude to $\phi$ are normally interpreted as internal committed claims. Yet, according to such and such norms, you shouldn't do $\phi$ or according to such and such norms, it is rude to $\phi$ are not normally interpreted as committed claims.

\footnotetext{
${ }^{7}$ This is based on a recent case. A US-Israeli teenager, presumably Jewish, is suspected of being responsible for the most of the bomb threats made to Jewish Community Centers in the US in the beginning of 2017.
} 
Normative or evaluative claims with embedded clauses have an internal committed reading only if additional information in the common ground entails that the speaker is committed to the relevant underlying normative practice. The same holds of normative claims of the form you ought to $\phi$, or positive evaluations like you are very generous to $\phi$.

There are uncommitted non-derogatory uses of pejoratives in constructions with the same form as paratextual and metatextual fictional sentences. But unlike normative or evaluative cases, uncommitted uses of pejoratives require that additional defeating information is available in context. The default interpretation under embeddings is still the committed offensive reading.

Moreover, the explicit addition of presumably defeating information, or its availability in context, does not generally suffice to cancel committed offensive readings, as (16) above shows. This suggests that the offensiveness of a pejorative results from a presupposition triggered by the use of the pejorative, not from a conversational implicature. Uncommitted non-derogatory cases may be explained either as the result of presuppositional cancellation, or as occurrences in quotational contexts. ${ }^{8}$

\section{References}

Bianchi, C. (2014). Slurs and appropriation: an echoic account. Journal of Pragmatics 66, 35-44.

Bonomi, A. (2008). Fictional Contexts. In P. Bouquet, L. Serafini, and R. Thomason (Eds.), Perspectives on Context, pp. 213-48. Stanford: CSLI Publications.

Burgess, J. P. (1983). Why I am not a nominalist. Notre Dame Journal of Formal Logic 24(1), 93-105.

Cepollaro, B. (2015). In defense of a presuppositional account of slurs. Language Sciences 52, 36-45.

Gazdar, G. (1979). Pragmatics: Implicature, Presupposition and Logical Form. New York: Academic Press.

Hart, H. L. A. (2012). The Concept of Law (3rd ed.). Oxford University Press.

Hom, C. (2008). The semantics of racial epithets. Journal of Philosophy 105(8), $416-440$.

Hom, C. (2012). A puzzle about pejoratives. Philosophical Studies 159(3), $383-405$.

\footnotetext{
${ }^{8}$ Cepollaro (2015) proposes a presuppositional account and argues against the two main objections to presuppositionalism about pejoratives. This paper does not aim to assess whether her arguments are successful, although I am inclined towards a closely related expressive presuppositional account of pejoratives.
} 
Hom, C. and R. May (2013). Moral and semantic innocence. Analytic Philosophy 54(3), 293-313.

Hom, C. and R. May (2015). Pejoratives as fiction. In David Sosa (Ed.), Bad Words. Forthcoming in Oxford University Press.

Jeshion, R. (2013). Slurs and stereotypes. Analytic Philosophy 54(3), 314-329.

Stanley, J. (2001). Hermeneutic fictionalism. Midwest Studies in Philosophy 25(1), 36-71.

Szabó, Z. G. (2001). Fictionalism and Moore's paradox. Canadian Journal of Philosophy 31(3), 293-307.

van Fraassen, B. C. (1980). The Scientific Image. Oxford University Press.

Williams, B. (1985). Ethics and the Limits of Philosophy. Harvard University Press. 